Puede citar este artículo como:

FERRER DEL Río, Estefania, «Successio ab intestato: a propósito de la muerte de Rodrigo de Mendoza, I marqués del Cenete», Revista de Historia Moderna. Anales de la Universidad de Alicante, n. ${ }^{\circ} 35$ (2017), pp. 467-496, DOI: 10.14198/RHM2017.35.14.

\title{
SUCCESSIO AB INTESTATO: A PROPÓSITO DE LA MUERTE DE RODRIGO DE MENDOZA, I MARQUÉS DEL CENETE
}

\author{
ESTEFANIA FERRER DEL RÍO \\ Universidad de Valencia \\ ferrer.delrio@gmail.com
}

\section{Resumen}

La muerte de Rodrigo de Mendoza, I marqués del Cenete, sin testamento se vio envuelta de la incertidumbre propia del fallecimiento de un noble con un cuantioso patrimonio heredado en gran parte de su padre, el gran cardenal de España, sin especificar ni repartir y con tres hijas menores huérfanas sin un albacea designado por él. El gobernador general de Valencia, Lluís de Cabanyelles, del círculo más íntimo del marqués durante su estancia en la ciudad del Turia, junto a otros partícipes y testigos, impulsó el proceso de inventariado de todos sus bienes cuatro días después de su defunción, apelando, asimismo, al emperador Carlos V para que confirmase al virrey del reino de Valencia y hermano del marqués, Diego Hurtado de Mendoza, como tutor de sus sobrinas. El objetivo del trabajo es esclarecer el complejo proceso seguido para la transmisión de los bienes de un destacado noble castellano afincado en Valencia fallecido ab intestato.

Palabras clave: marqués del Cenete, muerte sin testamento/inventario de bienes, Diego Hurtado de Mendoza, proceso de legitimación, s. XVI.

\begin{abstract}
Succesio ab intestato: Concerning the death of Rodrigo de Mendoza, I Marquis of the Cenete

The death of Rodrigo de Mendoza, I marquis of the Cenete, without a will was involved in the uncertainty of the death of a nobleman with a great heritage inherited much of his father, the grand cardinal of Spain, without specifying either distribute and three young daughters orphan without an executor appointed by him. The general
\end{abstract}


governor of Valencia, Lluís de Cabanyelles, the innermost circle of the marquis during his stay in the city of Turia, along with other participants and witnesses, conducted the process of inventorying all his possessions four days after his death, appealing to the emperor Carlos V to confirm the viceroy of the kingdom of Valencia and brother of the marquis, Diego Hurtado de Mendoza, as tutor of his nieces. The objective of this paper is to clarify the complex process followed for the transfer of property of a prominent castilian nobleman, settled at Valencia, deceased ab intestato.

Keywords: Marquis of the Cenete, death without a will, goods inventary, Diego Hurtado de Mendoza, legitimation process, XVI ${ }^{\text {th }}$ century.

A medida que la documentación consultada va desvelando aspectos hasta hoy desconocidos de la vida de un personaje tan peculiar como el primogénito del cardenal Pedro González de Mendoza, esto es, Rodrigo Díaz de Vivar $^{1}$ y Mendoza (1468ca. ${ }^{2}$-Valencia, 23 de febrero de 1523), I marqués del Cenete, esta nos ofrece nuevas interpretaciones que permiten ponderar su trayectoria con mayor precisión, pues no cabe duda de que a la hora de abordar las vicisitudes de cualquier miembro de la alta nobleza española en el tránsito de los siglos XV al XVI se nos abren numerosas hipótesis dada la complejidad de sus linajes. En este contexto, el marqués del Cenete es un buen ejemplo de la problemática que plantea su agitada biografía, parangonable, seguramente,

1. FERRER DEL RÍO, 34 (2016): 15.

2. Aunque la fecha de nacimiento del marqués sigue siendo una incógnita FALOMIR FAUS y MARÍAS, 6 (1994): 102, proponen que, pese a la datación dada por otros investigadores como SÁNCHEZ CANTÓN, 1942: 9-11, quien la sitúa entre 1466 y 1470, o GÓMEZ LORENTE, 1990: 82-85, quien afirma que el nacimiento del marqués debió darse no antes de octubre de 1467, el año de su nacimiento debía ser el 1473, porque en una inscripción desaparecida en La Calahorra datada en el 1510 se decía que el marqués tenía 37 años, fecha a su vez confirmada, según los autores, por la medalla conmemorativa de este, ya que su inscripción asegura que «el marqués contaba con 26 años cuando se forjó, lo que la dataría [...] en 1499», hipótesis que, además de coincidir con la inscripción del friso de La Calahorra, «coincidiría con el ahora documentado primer viaje de don Rodrigo a Italia.»Aun así, consideramos que su fecha de nacimiento debió de ser hacia el 1468, ya que en la documentación referente a la curadoría de los hijos de Mencía de Lemos, fechada el 3 de agosto de 1482, se asegura que Rodrigo cuenta con 14 años de edad y su hermano Diego con 12, Archivo Histórico Nacional, Sección Nobleza (en adelante AHN, SN), Osuna, Papeles que se refieren a la curaduría de los hijos de Mencía de Lemos, Rodrigo y Diego de Mendoza (1482), C. 2028, D. 1. 
a las de Gonzalo Fernández de Córdoba, César Borgia, Hugo de Montcada y tantos otros destacados aristócratas que todavía encarnaron los ideales de la caballería entre los reinados de los Reyes Católicos y Carlos V.

Un periodo convulso en la historia de aquella España imperial que a medida que es mejor conocido a través del testimonio de muchos de quienes la hicieron posible, con sus claros y sombras, coincide, asimismo, con la introducción de los modelos nacidos con el Humanismo en aquella Italia tan familiar a los intereses hispánicos, especialmente gracias a la vinculación del reino de Nápoles y Sicilia a su política exterior. Esta coincidencia entre los valores caballerescos, tan afines a la Edad Media, y los ideales de Renacimiento se irán conjugando hasta conformarse en ellos ejemplos de nobles «modélicos» donde sus gestas militares tendrán correlación con una cada vez más esmerada formación humanística a través de la adquisición de obras de arte, orfebrería, tapices, instrumentos musicales, armas, vajillas suntuosas, tejidos preciosos, e incluso merced a la formación nutridas bibliotecas compuestas por algunas de las obras más importantes de la literatura occidental, mediante ediciones finas y lujosas, hasta convertirse en verdaderos tesoros bibliográficos.

El caso valenciano es sintomático de esta confluencia a la que aludimos si contemplamos, entre otros, los casos de Juan de Borja, duque de Gandía, Alfonso de Aragón, duque de Segorbe, Serafín de Centelles, conde de Oliva, Lluís de Cabanyelles, señor de Benissanó, Johann de Brandenburgo-Ansbach, marqués de Brandenburgo, Jerónimo de Vich y Vallterra, señor de Llaurí, o Fernando de Aragón, duque de Calabria, contemporáneos de nuestro protagonista.

\section{Vicisitudes de un título nobiliario peculiar: el marquesado del Cenete}

Rodrigo de Mendoza, como titular del mayorazgo del Cenete desde $1491^{3}$, además de otras posesiones en los reinos de Valencia y de Castilla legadas por

3. AHN, SN Osuna, Mayorazgo de la villas de Cenete, fundado por el cardenal, arzobispo de Toledo a favor de su hijo Rodrigo, C. 1760, D. 10. Es el 3 de marzo de 1491, en Guadalajara, cuando Pedro González de Mendoza le entrega a Rodrigo las siete villas que había obtenido del monarca en tierras reconquistadas, las del marquesado del Cenete (DÍAz LÓPEZ, 23 (2011): 210): Aldeire, Calahorra, Ferreira, Dólar, Huéneja (PÉREz Boyero, 1997: 31; Espinar Moreno, Ruiz PÉrez, y Ruiz PÉrEz, 1985: 95-101), Jerez del Marquesado, Lanteira y Alquife, además de otros bienes que, si bien no aparecen 
su padre, acumuló a lo largo de su vida otros títulos y propiedades gracias a sus dos matrimonios con Leonor de la Cerda y Aragón (1493-1497) y María de Fonseca y Toledo (1502-1521) ${ }^{4}$, lo que le convirtieron en uno de los hombres más ricos de su tiempo. Sin embargo, el marqués hizo gala durante su vida de un carácter complejo ${ }^{5}$, por no decir polémico, en muchos de sus actos ${ }^{6}$, además de participar en las guerras de Granada, en las campañas de Italia y en las Germanías de Valencia ${ }^{7}$, encarnando el modelo de hombre instruido en $\operatorname{armas}^{8}$ que procuró dimensionar sus acciones a través del coleccionismo, al que tan afín eran algunos miembros destacados de su linaje: los Mendoza.

Avecindado en el reino de Valencia en sus posesiones de Ayora, entre 1520-1523 lo encontramos domiciliado en unas dependencias del palacio arzobispal de Valencia, lugar frecuentado por la alta nobleza regnícola ${ }^{9}$, muy probablemente por la inseguridad causada por las acometidas agermanadas y desde donde poder ayudar a su hermano, Diego Hurtado de Mendoza,

mencionados en ninguno de sus mayorazgos, sí llegó a poseer en los términos de las ciudades de Guadix y Granada. En el reino de Valencia, poseía el castillo y la villa de Ayora y los lugares de Alcosser, Alasquer y Alberic. Esto nos da a entender el verdadero fin que perseguía el cardenal Mendoza: ascender social y políticamente a su progenie. En pocos años, Rodrigo de Mendoza pasó de ser un hijo ilegítimo de un cardenal a marqués Domínguez OrTiz, 1973: 72; RUIZ PÉREZ, 14 (1984-1985): 294; EsPINAR MORENO, RuIz PÉREZ, y RuIz PÉREZ, 1985: 95-101; GÓmEZ LORENTE, 1990: 138; SORIA MESA, 1997: 49-50, 61-62; MARTín Civantos, 30 (2003-2004): 376-377. A este título se sumaron el de I conde del Cid (CATALinA GARCÍA, 1899: 84), señor de Ayora y otras posesiones tanto en Castilla como en el reino de Valencia que, cuidadosamente, había ido adquiriendo su poderoso progenitor (GÓMEZ LORENTE, 1990: 138).

4. El cual le aporta los señoríos de Coca y Alaejos, a pesar de que Alonso de Fonseca, poco antes de fallecer la había desheredado. Archivo General de Simancas (en adelante AGS), CME, Juro a favor de doña Mayor de Fonseca, 87, 21.

5. CATALinA GARCÍA, 1899: 665-681. MARCH, 24/93 (1951): 47-51.

6. MARCH, 24/93 (1951): 47-51. FRANCO SILVA, 9 (1982): 453-490; 1992: 217-227. PONS FUSTER, 33 (2007): 117-148.

7. DURAN, 1984: 14-16.

8. Una educación, centrada, tradicionalmente, en el ejercicio de las armas y la preparación militar y, por tanto, en su formación donde eran valoradas las prácticas que le proporcionan fuerza, agilidad o destreza física, tales como montar a caballo, cazar, ejercitarse con las armas, etc., evolucionará hasta un nuevo tipo de educación en el que, sin olvidar esta preparación física y guerrera, primero primaba el cultivo del espíritu y el ingenio. VARELA, 1983: 26 y ss. FERRER DEL RÍo, 41 (2015): 91-112.

9. FERRER VALls, 2007: 185-200. GÓMEZ-FERRER, 22 (2010): 35-37. 
entonces virrey ${ }^{10}$. De esta estancia en la capital del Turia en la que participó activamente tanto en acciones bélicas como en complejas negociaciones, sabemos que incluso padeció presidio en Xàtiva junto al duque de Calabria ${ }^{11}$, su futuro yerno a título póstumo ${ }^{12}$.

Como hemos señalado, poco después de establecerse en Valencia con María de Fonseca y sus tres hijas, Mencía, Catalina y María, acaeció la muerte de su esposa el 16 de agosto de 1521, para lo que el marqués dispuso su sepultura en el monasterio de clarisas de la Trinidad de dicha ciudad ${ }^{13}$, concretamente en la capilla contigua al ábside de la iglesia de dicho monasterio, seguramente la primera situada en el lado de la Epístola, la más cercana al altar y a la sacristía; un lugar emblemático, a su vez, por ser el elegido por la reina María de Castilla, cuyo sepulcro se halla en el claustro, ubicado en el lado del Evangelio ${ }^{14}$. A pesar de que su demarcación parroquial pertenecía a la iglesia de San Esteban ${ }^{15}$, el cenobio de clausura fue el lugar designado por su esposo para que reposaran los restos de su cónyuge dado el prestigio que la orden tenía por albergar en su claustro los despojos de la mujer de Alfonso el Magnánimo y de otros significados benefactores.

Una pérdida especialmente sensible debido a la historia sentimental, particularmente intensa, que vivió el marqués en sus segundas nupcias con María de Fonseca. Primogénita de Alonso de Fonseca, señor de Coca y Alaejos, que tuvo en su tierna juventud un amor tan apasionado como problemático con Rodrigo de Mendoza, para desposarse en secreto en $1502^{16}$, a pesar de la oposición paterna, que recurrió a la reina Católica para que desautorizara

10. Diego Hurtado de Mendoza es nombrado virrey y lugarteniente de Valencia en 1520, hasta el 1523 en que es sustituido por Germana de Foix: AHN, SN, Osuna, Título de virrey de Valencia que expidió Carlos I a favor de Diego Hurtado de Mendoza conde de Mélito, C. 1934, D. 1.

11. Arciniega, 2001: 166-179. Almenara Sebastià y Pardo Molero, 2012: 31-32.

12. El emperador Carlos V concreta el matrimonio entre Mencía de Mendoza, viuda desde el 14 de septiembre de 1538, con el viudo de Germana de Foix, el duque de Calabria, en 1541, uniendo así dos grandes casas y, por ende, su extenso y rico patrimonio.

13. AHN, SN, Osuna, Protocolos del notario Joan Sobrevero, C. 1342, D. 7-10. SÁNCHEZ CANTÓN, 1942: 20. CARrasco Martínez, 25 (2000): 238. FERRER DEl Río, 32 (2016): 245-258.

14. BeNito GOERLiCH, 1998: 54-57.

15. MARCH, 24/93 (1951): 59-60.

16. Catalina García, 1899: 665-681. 
dicha unión encarcelando a Rodrigo en las fortalezas de Cabezón ${ }^{17}$ y posteriormente de Simancas ${ }^{18}$ y a María en la de Zamora ${ }^{19}$ antes de ser trasladada al monasterio de las Huelgas en Valladolid ${ }^{20}$. En contra de la voluntad de la propia Isabel I, que lo mantuvo preso hasta su muerte en noviembre de $1504^{21}$, y de la de su familia política, el marqués pudo tener contacto con su esposa $^{22}$, llegando a raptarla con su beneplácito tras su puesta en libertad para trasladarse al castillo-palacio de Jadraque ${ }^{23}$. Este matrimonio ${ }^{24}$ fue legitimado en una primera instancia por Julio II en el año $1504^{25}$, considerando, a su vez, ilícito el casamiento forzado concretado por su padre con su sobrino y, por tanto primo hermano de María, Pedro Ruiz de Fonseca y Alarcón.

Probablemente, los meses posteriores al fallecimiento de María de Fonseca no fueron fáciles para el noble Rodrigo, pues a la desaparición de su esposa se sumaba el cuidado y la educación de sus tres hijas menores de edad en un contexto en el que la revuelta de las Germanías se encontraba en su máxima efervescencia. El apoyo a su hermano frenando el avance de los agermanados llevó a Rodrigo a participar en la captura del Encubierto en Burjassot ${ }^{26}$ para su posterior ejecución, seguramente un acto que celebraría con regocijo después

17. AGS, CCA, Prisión de Rodrigo de Mendoza, marqués de Cenete, CED. 7, 15, 4.

18. AGS, CCA, Prisión en Simancas de don Rodrigo de Mendoza, antes preso en Cabezón, CED. 9, 192, 9.

19. AHN, SN, Osuna, Cédula por la que se decreta prisión para María de Fonseca[Toledo]en la fortaleza de Zamora, C. 419, D. 381.

20. SÁNCHEZ CANTÓN, 1942: 15-16.

21. AGS, CCA, Alzamiento de carcelería al marqués de Cenete, CED. 9, 249, 1.

22. AHN, SN, Osuna, Cédula por la que se dispone que se refuerce la vigilancia sobre María de Fonseca[Toledo]para evitar su fuga, C. 419, D. 374.

23. SÁNCHEZ CANTÓN, 1942: 15-16.

24. En su celebración estuvieron presentes la propia madre de María dando, por consiguiente, su visto bueno, así como dos testigos. CATALina GarCía, 1899: 668-669.

25. AHN, SN, Osuna, Proceso sobre el matrimonio de Rodrigo de Mendoza, marqués de Cenete y María de Fonseca, hija de Alfonso de Fonseca, señor de Alaejos, alegándose anterior matrimonio de María con Pedro Ruiz de Alarcón, impedido por consanguinidad, CP. 245, D. 3-11.

26. DURAN, 1984: 14-16. El primer Encubierto conocido fue Enrique Manrique de Ribera, un judío converso de Orán asesinado en mayo de 1522, al que le siguieron otros Encubiertos: Joan Bernabé, Antón Navarro y Joan lo Portugués (GARCÍA CÁRCEL, 2006: 44-45). 
del quebranto ocasionado por las revueltas en sus posesiones valencianas y de su circunstancial encarcelamiento en la prisión real de Xàtiva.

\section{La problemática legal de una mors repentina en el seno de la alta nobleza}

Pero la muerte le sobrevino, probablemente, de forma súbita el 23 de febrero de $1523^{27}$ en las dependencias del palacio arzobispal. Este fallecimiento sucedió sin haber testado, por consiguiente, sin tan siquiera haber podido hacer partícipe a sus más allegados o incluso a su primogénita, Mencía, de sus últimas voluntades, ya que en las horas posteriores a este triste acontecimiento tuvo que hacerle frente la nueva marquesa del Cenete siendo todavía adolescente. Esta mors repentina, desde la Edad Media, estuvo considerada como infame y vergonzosa ${ }^{28}$, sobre todo porque un noble instruido en armas que había participado activamente en algunas de las guerras y revueltas de más repercusión de la época merecía un final digno de su estirpe y sus acciones, puesto que en una sociedad creada sobre modelos caballerescos y militares, esta muerte súbita e indigna no se extendía a las nobles víctimas de guerra ${ }^{29}$.

Rodrigo dejaba un notable patrimonio sin especificar, unos cuantiosos bienes sin repartir, unas hijas sin albacea ni tutor, las incertidumbres propias de cualquier fallecimiento se acrecentaban en el caso del primogénito del Gran Cardenal. ¿Cómo iba a ser la sepultura y los funerales que debía recibir? ¿Qué iba a ser de sus hijas? ¿Hasta dónde alcanzaban sus dominios? ¿Quién debía heredar qué y cómo se distribuiría su patrimonio? Todas estas dudas debían de haber sobrevenido al entorno más inmediato del marqués, pero, sobre todo, a su primogénita, Mencía, quien de repente debía hacerse cargo, al menos, de todo lo relativo a las exequias de su padre. Es por ello que, con la ayuda y consejo de los amigos de su desdichado progenitor, Lluís de Cabanyelles y Antonio de Luna, hizo llamar al notario Joan Sobrevero ${ }^{30}$, quien ya había estado al servicio del marqués por unos altercados acaecidos

27. EsCOLANO, 1611: 580, informa que fue una mujer quien arrojó una piedra que impactó en la cabeza de Rodrigo de Mendoza, hecho que da a entender que quizá este traumatismo le produciría poco después la muerte.

28. ARIÈS, 1983: 17.

29. ARIÈS, 1983: 19.

30. AHN, SN, Osuna, Depósito del cadáver de Rodrigo de Mendoza, marqués del Cenete en el Convento de la Santísima Trinidad de Valencia, C.1847, D.5, ff. 2-3. 
en la misma ciudad años atrás ${ }^{31}$, para que dejara por escrito el acuerdo con la abadesa del monasterio de la Santísima Trinidad, en nombre también de las monjas clarisas de la orden, para que su padre recibiera sepultura junto a su madre. A pesar de la rapidez con la que se llevan a cabo los pormenores de dicho entierro, ya que el mismo día del fallecimiento se perfilan los detalles tanto del sepelio como de la donación pecuniaria que debía ofrecer la familia a cambio, Mencía deja bien patente el deseo de que su padre reposara eternamente con su progenitora, seguramente un anhelo del que el propio marqués le haría partícipe pero que no dejó escrito, que sepamos.

Cuatro días después del óbito del marqués, el notario Jaume Bonavida ${ }^{32}$, su apoderado, llamado por los mismos Lluís de Cabanyelles y Antonio de Luna, comenzó el inventariado de todos los bienes de Rodrigo que se hallaban en los aposentos del palacio arzobispal donde residió sus últimos años, pero también los bienes que este tenía en el castillo de Ayora. En un primer momento, las hijas de Rodrigo de Mendoza no disponían de tutor alguno, por lo que el mismo entorno del marqués encabezado por los mencionados anteriormente, el señor de Benissanó y el vicario general de Valencia -los cuales ya habían sido partícipes en todo el proceso de su entierro-, recurrieron rápidamente al registro de todo su patrimonio mueble y semoviente que posteriormente había de ser repartido entre sus herederas ${ }^{33}$ con el fin de ejercer un control provisional sobre todos estos bienes y con ello evitar su extravío, sustracción o incluso su robo.

En la documentación relativa al inventario el notario había procedido a identificar los objetos del interior de las diversas cajas que el marqués había traído consigo a Valencia, seguramente los que tenía en más gran estima, entre los que caben destacar las obras médicas de Galeno ( «Item tres volums de libres de medicina de emprenta, cuberts de pergamí, intitulats: Primum, secundum et tercium volumen Galieni»), un ejemplar de Tolomeo («Ítem altre libre de emprenta, ligat en posts, intitulat: Lo Tolomeu»), Lo Crestià y el Dotzè del

31. PONS FUSTER, 33 (2007): 117-148.

32. Así como nos informa el notario Jaume Bonavida en el AHN, SN, Osuna, Inventario de los bienes muebles y semovientes relictos de Rodrigo Mendoza, marqués del Cenete, que se hallaron en el Palacio Arzobispal de Valencia, C. 1906, D. 1, cuya redacción y catalogación se inició el 27 de febrero de 1523.

33. FLANDRIN, 1979: 96-101. 
Crestià de Eiximenis impresos en Valencia en 1483 y 1484 («Item altre libre de emprenta, ligat en post, intitulat: Lo primer del Cristià», «Ítem un libre de emprenta, ligat en post, intitulat: Lo dotzè de Crestià»), algunos volúmenes de la literatura humanística italiana de Dante y Petrarca («Item hun Dant, de emprenta, quadernat en paper engrutat, cobert de cuyro burell», «Ítem hun Petrarca, quadernat també en posts e cubert ab una aluda vermella, segons los dessusdits»), o un Cancionero General («Item hun Cancioner General, enquadernat en pergamí»), de entre los más de seiscientos libros de su colección que se encontraron en su habitación, además de telares, tapices, joyas de oro de gran valor ${ }^{34}$, armas, etc. Continuó con el proceso el 8 de marzo, pero, en esta ocasión, en su residencia de Ayora. Allí es donde se hallaba la mayor parte de sus posesiones materiales, también en cajas, desde el grueso de su exquisita biblioteca a enseres personales, domésticos e incluso esclavos. Curiosamente, en esta fase del proceso trece días después del fallecimiento inesperado de Rodrigo de Mendoza, ya estaba presente su hermano, Diego Hurtado de Mendoza, hasta entonces virrey de Valencia, como tutor y albacea tanto de sus sobrinas como del patrimonio que su hermano dejó sin repartir.

La presencia de Diego Hurtado de Mendoza en el proceso de inventariado de los bienes de Ayora a partir del 8 de marzo de ese año no era casualidad. El día anterior, el mismo Lluís de Cabanyelles, general gobernador de la ciudad y reino de Valencia además de camarlengo real, quien verdaderamente había hecho de tutor tanto de Mencía de Mendoza como de sus hermanas desde la muerte del marqués, ayudándolas en todos los quehaceres en torno a este suceso, había requerido la confirmación por parte del emperador Carlos V para que el propio conde de Mélito fuera el tutor y, a su vez, albacea de las hijas del marqués, sus sobrinas, que en aquel momento contaban con aproximadamente 15,14 y 8 años respectivamente ${ }^{35}$.

El señor de Benissanó se dirige al rey en nombre de Mencía, quien ha requerido de sus servicios, ya que el marqués del Cenete, además de no testar, tampoco había designado tutor alguno de sus hijas menores, así que urgía

34. AHN, SN, Osuna, Memoria de joyas de oro, que la marquesa del Cenete tomó de la cámara del marqués Rodrigo de Mendoza su padre, difunto, en cuenta de su legítima, C. 1768, D. 14 .

35. Véase apéndice documental II. 
decretar y elegir una persona que cumpliera esa función. Y como el familiar más directo que tenían Mencía y sus hermanas era su tío paterno Diego, tanto el mismo Cabanyelles como los testigos presentes, micer Francesc d'Artés y micer Damià Andrés ${ }^{36}$, ciudadanos de la capital del Turia, deseaban designarlo a él, ya que no había otro familiar en Valencia con la consanguineidad y cercanía a las hijas de Rodrigo de Mendoza para desempeñar tal papel que el propio conde.

Acogiéndose a los Fueros de Valencia, Cabanyelles y los ya citados testigos hacen partícipe al monarca de que han provisto que la tutela de las menores dependiera de Diego Hurtado de Mendoza, dotándole así del poder para administrar y regir tanto a sus sobrinas y todo lo relativo a lo que estas pudieran necesitar como también de los bienes que su hermano dejó «sin control ni gestión». Una tarea que también se encargaría de supervisar que Diego la cumpliera debidamente a través de Lluís de Cabanyelles, además de Guillem Ruiz de Corella ${ }^{37}$, conde de Cocentaina, y los nobles Joan Ferrandis de Heredia ${ }^{38}$ y Melchor de Perellós ${ }^{39}$; así como de Gaspar Felip Cruillles, ciudadano de Valencia ${ }^{40}$. Una labor que Diego debía llevar a cabo sin ningún tipo de privilegio o derecho, puesto que era una función que debía cumplir con integridad al conocer la situación de sus sobrinas huérfanas, pero, además, porque todo se había pactado de esa forma.

36. VALOR MONCHO, 26 (2000): 227-242; 19 (2001): 16-17.

37. Guillem Ruiz de Corella, V conde de Cocentaina, llegaría a emparentar con los Mendoza, puesto que más tarde se desposaría con Brianda Hurtado de Mendoza, hija del mismo Diego Hurtado de Mendoza y Ana de la Cerda.

38. Juan Ferrrandis, o Fernández, de Heredia, fue un poeta valenciano, algunas de las composiciones líricas del cual fueron recogidas por Hernando del Castillo en el Cancionero General. FERRER VALLS, 2007: 191.

39. Melchor de Perellós ya tenía relación con Diego Hurtado de Mendoza, puesto que participó junto al entonces virrey contra los agermanados reuniéndose en la Vall de Alfondech junto a otros compañeros como los mencionados Ferrandis de Heredia o Cruilles, pero también con otros miembros destacables de la nobleza valenciana como Juan de Borja, Ginés de Perellós o Serafín de Centelles. QuAS, 2006: 87-88. Pero su vínculo con los Mendoza perduró, ya que participó posteriormente en el proyecto universitario que Mencía de Mendoza quería llevar a cabo en l'Estudi General de Valencia, en calidad de testimonio; además de otras ocasiones en que la marquesa del Cenete solicitó sus servicios. FELIPO ORTS, 1995: 147. FEBRER ROMAGUERA, 2003: 407-408.

40. Ciudadano de Valencia, además de jurado de la misma, perteneciente a la demarcación parroquial de San Salvador. FELIPO ORTS, 2004: 224 y 284; 2008: 32. 
Petición que el rey confirma nueve días más tarde, el 16 de marzo en Valladolid, momento en el cual, curiosamente, el conde de Mélito habría sido sustituido de su cargo de virrey, ya que la nueva lugarteniente de la ciudad y reino de Valencia era Germana de Foix, como así lo atestigua la documentación, haciendo mención a la que fuera reina de Aragón, segunda esposa de Fernando el Católico.

Mencía, Catalina y María ya disponían de un albacea que se hiciera cargo de ellas y del patrimonio que debían recibir, pero la confirmación de legitimidad de estas como hijas naturales de Rodrigo de Mendoza no se dio hasta el 3 de junio del mismo año ${ }^{41}$. Las hijas menores del difunto marqués disponían de un tutor, sus bienes ya habían sido registrados mediante un notario y ante la supervisión de los mismos testigos mencionados y que habían apelado al rey para que confirmara la tutela por parte del conde de Mélito, pero estas aún no habían sido declaradas legítimas con el fin de poder recibir su herencia. A pesar de que el 3 de octubre de 1492 se le otorga a Rodrigo de Mendoza la facultad de crear mayorazgo de sus bienes y heredades ${ }^{42}$-cabe recordar que su padre ya le había cedido el mayorazgo del Cenete el año anterior ${ }^{43}$-, seguramente coincidiendo con su futuro matrimonio con Leonor de la Cerda y la posibilidad de que esta engendrara un heredero, las hijas que este tuvo con su segunda esposa no habían sido declaradas legítimas, quizá porque al no testar, no dejó testimonio escrito de quién debía de heredar su patrimonio y, por ende, quiénes eran sus descendientes legales. Totalmente al contrario que el cardenal Mendoza, quien sí se encargó de obtener la legitimación de sus tres hijos, Rodrigo, Diego y Juan, por parte de la reina Isabe ${ }^{44}$ por la corona

41. Véase apéndice documental II.

42. AGS, RGS, Facultad a don Rodrigo de Mendoza, marqués del Cenete, para crear mayorazgo de todos sus bienes y heredades, los cuales detalladamente se expresan, Legajo 149210, 2.

43. Véase nota 3. En 1489 los RRCC cedieron al cardenal Mendoza casi la totalidad de la comarca del Cenete para satisfacer la deuda contraída con este -por haber contribuido a la financiación de la campaña- y que ascendía a 22 millones de maravedís. (PÉREZ BOYERO, 1997: 29)

44. AHN, SN, Osuna, Cédula de la Reina Católica por la que dio licencia y faculto a Pedro González Mendoza, cardenal de España, para hacer mayorazgo de sus bienes a favor de Diego y Rodrigo, hijos de Mencía Lemos y de Juan hijo de Inés de Tobar, legitimados, C. 1858, D. 7. 
de Castilla, del rey Fernando ${ }^{45}$ por la de Aragón, y de los pontífices Sixto IV, Inocencio $\mathrm{VIII}^{46}$ y Alejandro VI, puesto que por su posición eclesiástica y dada su relación concupiscente con Mencía de Lemos, madre de Rodrigo y de Diego, e Inés de Tovar, madre de Juan, si quería que sus hijos ilegítimos heredaran su patrimonio, primeramente hubo de legitimarlos para, a su vez, poder crear mayorazgo y que, por ejemplo, los bienes que él había recibido de su padre (los municipios de Monasterio y Campillo ${ }^{47}$ ), Íñigo López de Mendoza, marqués de Santillana, no retornaran al nuevo titular del marquesado como duque del Infantado, el hermano mayor del cardenal, Diego.

La iniciativa del proceso de legitimación de las hermanas Mendoza fue de Jaume Gassull -o Gaçull-, caballero subrogado de Jeroni Cabanyelles ${ }^{48}$, hijo de Lluís de Cabanyelles, y portavoz del gobernador de la ciudad de Valencia, y en la que comparece el notario Damià Burgal ${ }^{49}$, procurador de Diego Hurtado de Mendoza, ante la demanda de sucesión ab intestato de su hermano, Rodrigo Díaz de Vivar y Mendoza, interpuesta por Francesc Joan Cardona, notario, también procurador del conde de Mélito, el 8 de abril, por la cual Ramon de l'Hort, en representación de la Corte, teniendo en cuenta los testimonios aportados en dicha causa, expresa el consenso y acuerdo al que se ha llegado en reconocer como legítimas a las hijas de Rodrigo y María y en declarar que, a pesar de no haber hecho testamento, con la autoridad y confirmación de los Reyes Católicos, las tierras y el patrimonio pertenecientes al mayorazgo del

45. AHN, SN, Osuna, Legitimación de Rodrigo, Diego y Juan de Mendoza, hijos del cardenal de España y arzobispo de Toledo, Pedro González de Mendoza, y Mencía de Lemos, expedido por Fernando el Católico, C. 1760, D. 2.

46. AHN, SN, Osuna, Testimonio (1498) de la bula de Inocencio VIII por la que concedió a Pedro González de Mendoza, cardenal Arzobispo de Toledo y canciller mayor de Castilla, licencia para disponer de los bienes libres en testamento o codicilo, aún a favor de sus hijos si los tuviere, a cuyo efecto les reconocía como si fueran legítimos y en legitimo matrimonio, C. 1760, D. 1 .

47. FoulchÉ-DelbosC, 67 (1911): 121.

48. Jeroni de Cabanyelles, señor de Benissanó, era hijo del gobernador del reino de Valencia, Luis de Cabanyelles, a quien sustituyó en el cargo a su muerte, además de comendador de Santiago y capitán de la guardia de Fernando el Católico, a quien sirvió como embajador en Italia. PEREA RODRÍGUEZ, 2007: 248.

49. Notario y escribano que ya había trabajado para el marqués anteriormente, sobre todo, a raíz de sus segundas nupcias con María de Fonseca. FALOMIR FAUS y MARíAS, 6 (1994): 105. 
marqués (entre los cuales se encuentran el propio marquesado del Cenete, el condado del Cid, el palacio de la Calahorra, Jadraque y su tierra, la villa de Ayora y las baronías de Alberic, Alcosser, o Alasquer, Gabarda, Coca y Alaejos, aunque estas últimas no las nombra, la de Alasquer sí aparece en el inventario de bienes del marqués realizado por el notario Jaume Bonavida) sean para su primogénita Mencía y que el resto de bienes sean lícitos de repartición entre las tres hermanas. Ramon de l'Hort promulga dicha sentencia teniendo por testigos a Francesc Fernando y a Francesc Català, ciudadanos de Valencia; sentencia posteriormente ratificada por el escribano de la Corte Joan Llorens Roures.

Solucionada la problemática originada a raíz de la muerte repentina y sin testar del marqués del Cenete, Mencía, Catalina y María contaban ya con el patrimonio que les correspondía como herencia tanto por parte de su padre como de su madre, María de Fonseca. Mencía se convertía con casi 15 años en la nueva cabeza del mayorazgo, en una de las mujeres más pudientes del reino, es por ello que, en 1524, un año después de todo lo acaecido en el seno de su familia, el emperador concretó su casamiento con Hendrik III de Nassau-Dillenburg-Diet, señor de Breda, perteneciente a la alta nobleza de Flandes, que contaba por aquel entonces con 41 años, veintiséis más que Mencía, para quien sería su tercer matrimonio. Lejos de considerar este matrimonio como un mecanismo de control por parte de la monarquía sobre un patrimonio tan considerable como el que había sido recibido en herencia desde el cardenal Mendoza y del que Mencía de Mendoza se desprendió en gran parte durante las almonedas llevadas a cabo entre 1529 y 1535 en Valencia ${ }^{50}$, esta logró convertirse en una humanista en potencia. Su estancia en los Países Bajos le sirvió para formarse junto a Joan Lluís Vives ${ }^{51}$ y, aunque contempló la posibilidad de tener contacto con Erasmo, encuentro que no pudo conseguir ${ }^{52}$, para empaparse de todo el ambiente artístico-filosófico que en aquel momento se vivía en Europa, llegó a convertirse en una gran mecenas del arte, a la que muchos literatos valencianos, a lo largo de su vida y, sobre todo, a partir de su posterior estancia en Valencia por sus segundas nupcias

50. GÓMEZ-FERRER, 14 (2010): 231-246.

51. SOLERVICENS BO, 2003: 313-324.

52. SOLERVICENS BO, 2003: 318 y ss.

Revista de Historia Moderna, n. ${ }^{\circ} 35$ (2017) (pp. 467-496) | ISSN-e: 1989-9823 | ISSN: 0212-5862 
con Fernando de Aragón, duque de Calabria, dedicaban sus composiciones en señal de promoción social y agradecimiento ${ }^{53}$.

Sin embargo, aunque la historia de amor por la que María y Rodrigo habían luchado contra la adversidad paterna e incluso real parecía que reposaría junta para la eternidad en las clarisas, Mencía tenía otros planes, quizá porque quería proporcionar a sus padres un sepulcro digno de su rango, de un linaje relacionado con la monarquía y emparentado, por decisión de Pedro González de Mendoza, con el mismo Cid Campeador.

Es por ello que en 1535, en previsión de un posible fallecimiento repentino como le había sobrevenido a su padre y consciente de que lo haría sine prole después de algunos abortos, por lo que ningún descendiente pudiera hacer cumplir los deseos que en vida expresaría, dejó redactado su testamento en Burgos ${ }^{54}$, antes de que el emperador Carlos V, el 18 de marzo del año siguiente, le concediera la capilla de los Tres Reyes del convento de Predicadores de la capital levantina ${ }^{55}$ para que pudieran ser trasladados los restos de sus progenitores y descansaran en paz en un espacio privilegiado que se edificó para albergar los despojos del rey Alfonso el Magnánimo y de María de Castilla, siempre y cuando esta respetara los escudos de armas reales que en ella se hallaban. Mencía había conseguido su propósito: encumbrar la figura de su padre a la altura de un rey, tal y como él ya había hecho mención de equipararse al hacer que fuera enterrada su esposa en el mismo emplazamiento que la reina María de Castilla -y, posteriormente, serlo él-, dándole finalmente sepultura en una tumba de exquisito gusto renacentista genovés, esculpida en un delicado mármol blanco y para el que contó con

53. Como el catedrático de Poesía del Estudi General de Valencia, Joan Àngel González, quien le dedicó obras como Sylva ad Menciam Mendoziam (1539), además de otras composiciones poéticas en honor a su matrimonio con el duque de Calabria (BNE R/19833, f. 2r); Dionís Clemente, quien le dedica su obra Valerián de Hungría (1540); Miquel Jeroni Ledesma, catedrático de griego en la misma institución que González, cuya obra Graecarum institutionum compendium (1545) también contiene la dedicatoria a la marquesa del Cenete; o el mismo Joan Baptista Anyés -o Agnesio-, quien le dedicó gran parte de sus opuscula, entre otros.

54. AGS, Testamento de Mencía de Mendoza, Legajo 320.

55. AHN, SN, Osuna, Provisión Real de Carlos I y su madre en la que hacen donación a Mencía de Mendoza, Marquesa de Cenete y Condesa de Nassau, de la Capilla Real del Monasterio de Predicadores de Valencia, C. 1847, D. 6. 
los escultores Giovanni Battista Castello El Bergamasco, Giovanni Carlone y Giovanni Orsolino. La ostentosidad con la que figuran Rodrigo de Mendoza, cuya escultura lo muestra como el condottiero que fue en vida, y María de Fonseca contrasta con la sencillez propia de la Devotio Moderna con la que se hizo enterrar Mencía de Mendoza ${ }^{56}$, en señal de modestia a los pies de sus padres, cuya sepultura, que fue ultimada por su heredero, Luis de Requesens ${ }^{57}$, deja por simple testimonio una placa conmemorativa.

\section{Conclusiones}

Aunque lo relativamente lógico hubiera sido que el propio marqués, teniendo en cuenta el alcance de su patrimonio y la conservación de este a través de sus herederas $^{58}$, sobre todo del mayorazgo en la figura de su primogénita Mencía ${ }^{59}$, hubiera acudido a una escribanía para otorgar su testamento ${ }^{60}$, lo cierto es que, tal y como hemos comprobado a lo largo de nuestra investigación, la muerte le sobrevino repentinamente. No sabemos con seguridad si moriría ipso facto o estaría convaleciente durante unos días hasta su fallecimiento, el hecho es que su inesperada defunción le privó de ejercer su derecho a testamentar o a plasmar, extrajudicialmente, declaraciones testamentarias a sus más allegados ${ }^{61}$.

Bien es cierto que, por la rapidez con la que actuaron tras su fallecimiento tanto su primogénita como su círculo de amistades de más confianza, sin titubear a la hora de disponer su funeral y su sepultura ${ }^{62}$ y de proceder al inventariado de todo su patrimonio, intentando no dejar ningún cabo suelto, nos da a entender que seguramente Rodrigo de Mendoza sí diera fe, verbalmente, quizá con anterioridad a su «accidentado» deceso, de sus postrimeras voluntades.

La falta de provisión y de costumbre de testar cuanto antes -adelantándose a una posible enfermedad, accidente o avanzada edad- contrasta considerablemente con los ejemplos de su abuelo, el marqués de Santillana, de su padre, el cardenal Mendoza, e incluso, como hemos mencionado anteriormente, de

56. GARCÍA PÉREZ, 19-20 (2007-2008): 63-74.

57. MARCH, 1942: 372-373. SOLERVICENS BO, 2003: 313-324.

58. DOMÍNGUEZ ORTIZ, 1973: 87 y ss.

59. FELIPO ORTS y PÉREZ APARICIO, 2014: 317-318.

60. LORENZO PINAR, 1989: 81 y ss.

61. GARCÍA FERNÁNDEZ, 1996: 48-49 y 53-54.

62. GARCÍA FERNÁNDEZ, 1996: 50. 
su propia hija ${ }^{63}$. En el caso de Íñigo López de Mendoza, a sabiendas del mayorazgo que debía de continuar, testó en favor de sus descendientes ${ }^{64}$ (siendo el más beneficiado su primogénito, Diego Hurtado de Mendoza y Suárez de Figueroa, pues se convirtió en el cabeza de familia); al igual que Pedro González de Mendoza, quien, consciente del patrimonio adquirido gracias al papel que jugó durante el reinado de los Reyes Católicos y de la, a priori, ilegitimidad de su descendencia, realizó su testamento en el año $1494^{65}$, poco antes de su fallecimiento.

Una vez registradas todas sus propiedades, quedaba por solucionar el problema de la legitimación de sus hijas ${ }^{66}$, además de su albacea, para ello se dispuso de lo necesario para que, por una parte se reconocieran como herederas legítimas de Rodrigo de Mendoza, y, por otra, para que su pariente más cercano -tanto en proximidad física como familiar-, el conde de Mélito, fuera reconocido oficialmente para tal propósito. Aunque bien es cierto que, desde que se inició el proceso de registro de los bienes del marqués (febrero de 1523) hasta que fueron declaradas hijas naturales de este Mencía, Catalina y María (junio del mismo año), su tío no solo acató la decisión de encargarse de sus sobrinas y de que estas recibieran el patrimonio de su padre, sino que también fue destituido como virrey de Valencia en favor de Germana de Foix y acabó renunciando al cargo de tutor y curador que meses antes le había ordenado el rey ${ }^{67}$.

63. Un ejemplo prácticamente coetáneo al propio marqués nos demuestra que la muerte probablemente súbita también le había impedido cualquier declaración de voluntades. Es el caso del II duque de Alburquerque (1467-1526) quien, al fallecer sin testar, vio cómo todo su patrimonio tuvo que ser también inventariado por un notario, RUIz GARCÍA y CARCELLER CERVIÑo, 2002: 361-400.

64. AHN, SN, Osuna, Testamento y codicilio otorgado por Iñigo López de Mendoza, C. 1762, D. $10-11$.

65. AHN, SN, Osuna, Testamento otorgado por Pedro González de Mendoza, Cardenal Arzobispo de Toledo, C. 2023, D. 6. FERnÁndEz Collado, 2007: 24-26.

66. Teniendo en cuenta que el matrimonio de Rodrigo de Mendoza y María de Fonseca había sido considerado ilícito hasta la legitimación de Julio II (1504) -y aun así, esta problemática se alargó, a través de sus descendientes, hasta la confirmación final de la legalidad de dicho matrimonio realizado por fray Pedro de Álava (1594)-, sus hijas no eran consideradas naturales (CALDERÓN RANGEL, 2001: 109) y, por ende, no tenían derecho a heredar (LARA RÓDENAS, 1997: 116), por lo que su legitimación era necesaria para que pudieran recibir los bienes de su padre. FERRER DEL RÍO, 23 (2016): 13-34.

67. AHN, SN, Osuna, Cédula de Carlos I por la que confirmó el discernimiento de tutor y curador para las personas y bienes de Mencía de Mendoza, marquesa de Cenete y de sus 
A pesar de no haber dejado testimonio escrito el marqués del Cenete, no cabe duda de que su hija supo darle la sepultura que hubiera querido y que él mismo había dejado entrever al enterrar a su esposa frente a la difunta reina María. Rodrigo de Mendoza se convirtió en la personificación del caballero indomable, de carácter fuerte e incluso violento, intransigente con sus súbditos y vasallos ${ }^{68}$ e incluso con los usurpadores -los agermanados- de sus propios territorios en el reino de Valencia, pagando con prisión en dos ocasiones totalmente dispares: una, a causa de su amor prohibido, y, otra, por su implicación en la revuelta de las Germanías; pero, al mismo tiempo, del noble formado en la corte, con un gusto refinado para el arte, coleccionista insaciable que llegó a poseer una distinguida biblioteca al igual que su abuelo, el marqués de Santillana ${ }^{69}$, continuando así la heredada por su padre, e interesado por los logros del Quattrocento italiano, del que hasta en dos ocasiones pudo ser testimonio, puesto que además de convertir la fortaleza medieval de La Calahorra en todo un palazzo renacentista de la mano de Lorenzo Vázquez ${ }^{70}$, a quien tuvo preso haciendo honor a su controvertido carácter, también trajo consigo un libre de deboxos quadernat que parece corresponderse con el Codex Escurialensis 28-II-12 ${ }^{71}$, un manuscrito único con los bocetos de la ornamentación arquitectónica del Renacimiento maduro. Su muerte, sin embargo, no hizo honor a una vida digna del protagonista de un libro de caballerías, mas no así su sepultura parangonable a la de un monarca.

hermanas Catalina y María, hecho por el Gobernador de Valencia en Diego Hurtado de Mendoza, conde de Mélito, C. 1769, D. 1. De hecho, Diego comunica su renuncia a dichos cargos al rey quien, posteriormente, la confirma y la traslada al ya mencionado Jeroni de Cabanyelles, AHN, SN, Osuna, Provisión de Carlos I al General Gobernador de Valencia Jerónimo Cabanillas de que admita la renuncia del cargo de tutor y curador al conde de Mélito y cumpla esta cédula y otra anterior que inserta, C. 1934, D. 4(1).

68. RuIZ PÉREZ, 14 (1984-1985): 297-299. SORIA MESA, 1997: 124. DíAZ LÓPEZ, 23 (2011): 211.

69. SCHIFF, 1906: 1-448.

70. FALOMIR FAUS, 63/250 (1990): 263-270. Ruiz PÉREZ, 26 (2014): 167-200.

71. MARÍAS, 2 (1990): 117-130. FERNÁNDEZ GÓMEZ, 74 (1992): 123-162. FALOMIR FAUS y MARÍAS, 6 (1994): 104-108. SCAGLIA, 77/208 (2004): 375-383. MARÍAS, 63 (2005): 14-35. Aunque, en realidad, en el inventario de los bienes de Rodrigo de Mendoza aparecen dos de estos cuadernos bajo la descripción de libre de deboxos, ejemplares que se hallaban entre los bienes más preciados que el marqués del Cenete había traído consigo a Valencia. 


\section{Apéndice documental}

\section{3, marzo, 16. Valladolid}

A petición del gobernador general de Valencia Lluís de Cabanyelles, Carlos V nombra a Diego Hurtado de Mendoza, conde de Mélito, tutor de las hijas huérfanas de Rodrigo de Mendoza, I marqués del Cenete, su hermano fallecido sin haber testado.

AHN, SN, Osuna, Provisión de Carlos I confirmando el nombramiento hecho por el Gobernador del Reino de Valencia de Diego Hurtado de Mendoza, [príncipe de Mélito], como tutor y curador de sus sobrinas Mencía de Mendoza, [II] marquesa de Cenete, Catalina de Mendoza y María de Mendoza, CP. 225, D. 11.

NOS CAROLVS divina favente clementia flectus Romanorum imperator semper augustus, rex Germaniae, Joanna eius mater et idem Carolus Dei gratia reges Castellae, Aragonum utriusque Siciliae, Hierusalem, Hungariae, Dalmaciae, Croaciae, Legionis, Navarrae, Granatae, Toleti, Valenciae, Galleciae, Malloricarum, Hispalis, Sardiniae, Cordubae, Corsicae, Murciae, Giennis, Algarbii, Algezirae, Gibraltaris, Insularum Canariae, necnon insularum Indiarum et Terrae firmae Maris Oceani, archiduces Austriae, duces Burguntiae et Brabantiae et caetera, comites Barchinonae, Flandriae et Tirolis et caetera, domini Vizcaia et Molinae et caetera, duces Atthenarum et Neopatriae et caetera, Comites Rossillonis et Ceritaniae, marchiones Oristanni et Gotianifuit pro parte spectabilis ex dilecte nostrem Menciae de Mendoça marchionisse de Azenete maiestari nostrem revereter exibitum quoddam tutelae ex curae publicum instrumentum tenoris sequensis.

Nos don Luys de Cabanyelles cavaller, conseller, camarlench de la cessàrea e real Maiestat e portant veus de general governador de la ciutat e regne de València per auctoritat del dit nostre offici del qual plenament usam a instància e requesta de la Il-lustre dona Mencía de Mendoça, filla del Il-lustre don Rodrigo de Mendoça, quòndam marqués de Azenete, marquesa de Azenete, maior de quinze anys deduint en effecte ab scriptura e requesta per aquella posada devant nos e Cort nostram en lo present die de huy comptat set dies del mes de març del dit any de la Nativitat de nostre Señor Déu mil cincents 
vint-y-tres que lo dit Il-lustre señor don Rodrigo de Mendoça, marqués de Azenete, en sancta glòria sia, pare de aquella, és mort e passat de la present vida en l'altra sens fer testament ne altra derrera voluntat sobrevivint-li tres filles legítimes e naturals de aquell e de la Il-lustre dona María de Fonseca, quòndam marquesa e muller de aquell, és a saber ella dita proposant e les Il-lustres Dona Catherina e dona María de Mendoça, en menor edat constituÿdes, ço és la dita dona Catherina, de edat de quatorze anys, e la dita dona Maria, de edat de vuit anys, e per no haver fet testament lo dit Il-lustre señor marqués quòndam ne haver preÿt de tutor e curador és necessari decretar e assignar un tutor et curador a les persones e béns de ella dita proposant e de les dites ses germanes.

E com de justícia la dita tutela e cura pertanga al Il-lustre don Diego Hurtado de Mendoça, de honcle paternal ella dita, proposat e de ses germanes com sia germà ex utroque latere del dit Il-lustre señor marqués quòndam.

Per tal ella dita proposant en aquella millor via, forma e manam que dir, puxa ab la maior instància que pot e deu requerir e demanar-nos, placia provehir e manar, sia rebuda sumària informació de testimonis axí de la mort del dit Il-lustre señor marqués, son pare, e com és mort sens haver fet testament ni altra derrera voluntat, com encara que lo dit Il-lustre señor don Diego Hurtado de Mendoça és germà ex utroque latere e més del dit Il-lustre señor marqués, pare de aquella e maior en dies que nengú dels que huy resten, e constant-nos de les dites coses, nos placia declarar la tutela e cura de ella dita proposat e de les dites ses germanes prontament al dit Il-lustre don Diego Hurtado de Mendoça com a germà de dit Il-lustre señor marqués ex utroque latere e més, continuant en grau de parentela, que nengú altre e decretar aquell en tutor y curador de les dites persones de ella dita proposat e de les dites ses germanes, donant e atribuint poder per a regir e administrar les persones axí de ella dita proposant com de les dites ses germanes, segons en la dita requesta és contengut.

E nos, vista la dita requesta e lo contengut en aquella aconsellat del noble Leander de Loris, doctor en cascun dret, assessor ordinari de la nostra Cort, havem provehit e ser rebuda la dita sumària informació de testimonis e que suversivament hi seria proveÿt e après rebuda la dita informació de testimonis, havem proveÿt a consell del dit noble assessor de la dita nostra Cort perquè per les dites deposicions dels dits testimonis et als notòriament 
consta y altrament se descobre com dit Il-lustre don diego de Mendoça éser més propimque en grau de parentela e consanguinitat ex utroquelatere a les dites e premisses: Il-lustre marquesa e altres germanes dona Catherina e dona María de Mendoça, menors e consegüentment inseguides les disposicions dels furs del present regne, axí com a més propincque segons dessús dit spectar e pertànyer la tutela e cura de aquelles e per ço ab la dita provisió havem provehit que sia decretada, axí com ab la present a vos dit Il-lustre don Diego de Mendoça, manam éser-vos decretada a les coses dessús requestes, prestats jurament e obligació feta ut in forma e caució opportuna e necessària, per tal confiant de la bondat e indústria e legalitat de vos, dit Il-lustre don Diego Hurtado de Mendoça, comte de Mélito, vos decretam en tutor e curador de les persones de les dites: Il-lustre Dona Mencía de Mendoça e doña Catharina e doña María de Mendoça, germanes filles del dit Il-lustre don Rodrigo de Mendoça, quòndam marqués de Azenete, en menor edat constituÿdes.

Donant e tribuint-vos poder per a regir e administrar les persones, axí de la dita dona Mencía de Mendoça com de les dites dona Catherina e dona María de Mendoça, germana de aquella, en la qual dita cura e la forma e manam dessús dites, assistam bé e lealment, e fent tots los actes faedors en la dita tutela e cura e concernents e necessaris de aquella, e que sobre la dita cura e actes e coses de aquella, sian sol-lisit e curos, axí com tot bon tudor e curador fer pot e deu, e és tengut e obligat de fer.

Car nos, per auctoritat del dit nostre offici, haurem per ferm e agradable tots e qualsevol actes que en la dita tutela e cura e coses de aquella per vos seran fets e anantats sots obligació dels béns de la dita tutela e cura.

E lo dit Il-lustre don Diego Hurtado de Mendoça, comte de Mélito, acceptant la dita tutela e cura en la forma e manam dessús dites voluntàriament e de son bon grat promés al dit molt spectable señor governador en poder del notari scrivà de la sua Cort, axí com a pública e audtèntica persona per aquell e per tots aquells dels quals és o per a éser interés de present o en sdevenidor stipulant o rebent haver-se bé o lealment en sol-licitaren la dita cura e actes de aquella ab bo e sencer enteniment junt son poder, per les quals coses e sengles de aquelles obliga al dit molt spectable señor governador tots sos béns, drets e accions mobles, immobles e semovents privilegiats e no privilegiats haguts e per haver hont que sien o seran, e jura a nostre Señor Déu y als Sants Evangelis de aquell de la sua mà dreta, corporalment tocats les dites coses e 
sengles de aquelles, fermament tenir, observar e cumplir e contra aquelles no venir per neguna manera ni rahó, e per maior tuÿció e seguretat de les dites coses done en fermantes e principals obligats ab ell e sens ell a cascú per si e que lo tot en la dita tutela e cura de les dites persones de les dites Il-lustres dona Mencía e dona Catharina e dona María de Mendoça, germanes e filles del dit Il-lustre Don Rodrigo de Mendoça, quòndam marqués d'Azenete, lo spectable don Guillem Ruiz de Corella, comte de Cossentayna e los nobles Joan Ferrandis de Heredia e Don Melchior de Perellós, e lo magnífich en Gaspar Phelip Cruÿlles, donzell, habitadors de la ciutat de València, ço és, tots ensemps e cascú de aquells per si e per lo tot, los quals dits don Guillem Ruyz de Corella, Compte de Concentayna, don Joan Fernández de Heredia e don Melchior de Perellós e en Gaspar Felip Cruÿlles, com fossen presents, foren interreogats per lo dit notari scrivà de la Cort si ells tots ensemps e casacú de aquells per si e per lo tot feyen la dita fermança e principal obligació al dit Il-lustre don Diego Hurtado de Mendoça en la dita tutela e cura de les dites persones de les dites Il-lustres: dona Mencía, dona Catherina e dona María de Mendoça, filles del dit Il-lustre don Rodrigo de Mendoça, quòndam marqués de Azenete, en menor edat constituÿdes e dixeren e respongueren que sí.

E per ço obligaven al dit molt spectable señor governador tots sos béns, drets e actions mobles, immobles e semovents privilegiats e no privilegiats haguts e per haver, honque sien o seran.

Renunciant quant en açò als beneficis de partida, acció, nova constitució, a la Epístola de diví Adrià e al fur de València, que vol que lo principal sia convengut ans que la fermansa.

Sotméter-se per les dites coses al for distret, juhí, examen e jurisdicció del dit señor governador e a lurs propis fors, e de fors jutges ordinaris expressament e de certa sciència per special pacte.

Renunciant e renunciant encara a la ley, si convenint ffiat de jurisdicció de tots jutges, en tot e qualsevol altre dret, ley, fur, privilegi, us costum consumció e ordinació contra les dites coses, venint fetes foren les dites coses en València a VII dies del mes de març del any de la Nativitat de nostre Señor Déu mil cincents vint-y-tres. Senyal de nos, don Luys de Cabanyelles, governador.

Senyals de nosaltres: don Diego Furtado de Mendoça, tudor e curador, Don Guillem Roiz de Corella, don Joan Ferrandis de Heredia, don Melchior de Perellós e en Gaspar Felip Cruilles, fermances dessús dits qui les dites 
coses fermam, loam e aprovam presents testimonis foren a les dites coses los magnífichs micer Francesc d'Artes e micer Damià Andrés, doctors en cascun dret, habitadors de València.

Registrata in VIII manu litigiorum de anno M. $^{o}$ D. ${ }^{o}$ XXIII. ${ }^{o}$, folio XVIII. ${ }^{o}$, supplicato itaque nobis pro parte dicte spectabilis Mencie de Mendoça, marchionisse ut preinsertum tutelae et curae instrumentum omniaque et singula in eo contenta laudare et approbare ac auctoritzare ex nostri solita munificentia dignaremur. Nos certis et justis mori respectibus supplicationi ipsius benigne annuentes tenore presentisde certa sciencia regiaque auctoritate nostra deliberate et consulto instrumentum memoratum omniaque et singula in eo contenta tanquam rite et recte facta eidem marchionisse sororibusque suis permissis laudamus, approbamus et confirmamus eique auctoritatem regiam nostram, interponimus pariter et decretum. Nostreque huiusmodi laudtionis approbationis decretique et auctoritatis inperposicionis munimine seu presidio roboramus. Itaque dicta laudatio, approbatio decretique et auctoritatis interpositio sit et esse debeat prefatis sororibus ac ómnibus aliis etiam ad quos attineat realis stabilis atque firma. Nullumque sentiens in iudicio vel extra dubietatis obiectum aut noxae alterius detrimentum, in suo semper robore et firmitate persistant.

Quapropter serenissimam Germanam reginam Aragonum matrem nostram charissimam, ac locumtenentem generalem in dicto Valenciae regno affectuose rogamus. Prefato autem gerentibus vices nostri generalis gubernatoris ac aliis etiam officialibus regni maioribus et minoribus et eorum locumtenentum presentibus et futuris eadem regia auctem nostra dicimus et mandamus ad incursum nostris indignationis et ire peneque florennorum auri Aragonum mille nostris inferendorum erariis quatenus nostram huiusmodi laudationem approbationem decretique et auctoritatis interpositionem ac omnia et singula precontenta teneant firmiter et observent tenereque et observari faciant inviolabiter per quoscumque cauti secus agere, fierive permittere ratione aliqua sive causa pro quanto prefata serenissima regina nobis morem genere ceteri vero officiales nostri penam preappositam cupiunt non subire.

In cuius rei testimonium presentem fieri ius simus nostro communi quo antequam ad Sacrum Imperium electi essemus, utebamur sigillo, cum nondum alia fabricata fuerint impendenti munitam.

Datum in oppido Vallesoleri die XVI mensis marcii anno a Nativitate Domini millesimo quingentesimo vicesimotercio regnorumque nostrorum videlicet 
electionis Sacri Imperii, anno quinto, regine Castelle, Legionis, Granate, et caetera, XX. ${ }^{\circ}$, Navarre nono, Aragonum vero utriusque Siciliae, Hierusalem et aliorum octavo, regis vero omnium octavo.

Yo el Rey.

\section{3, junio, 3. Valencia}

Sentencia por la cual se declaran hijas legítimas y naturales de Rodrigo Díaz de Vivar y Mendoza, marqués del Cenete, Mencía, Catalina y María, después de su muerte ab intestato para poder heredar sus bienes iure successionis.

AHN, SN,Osuna, Declaración de herederos ab intestato del marqués del Cenete, C. 1934 , D. 12.

Procés de sentència de successió ab intestato [e legítimes] ${ }^{72}$ dona Mencía y dona Catherina y dona Maria de Mendoça. Ano de 1523. ${ }^{73}$

Post modum vero die intitulata tercia menssis junii anno a Nativitate Domini millessimo quigentessimo vicessimo tercio, davant lo magnífich Jaume Gaçull, cavaller sorrogat del molt noble don Hierònim de Cabanyelles, cavaller, conseller, camarlench e capità de la guarda de la cessària real majestat, e portant veus de general governador de la present ciutat e regne de València, comparech lo favorable e discret en Damià Burgal, notari, procurador del dit molt Il-lustre don Diego de Mendoça, compte de Mélito, en dit nom el qual fon publicada la sentència o declaració del señor següent Ihesús.

E lo magnífich mossén Jaume Gaçull, cavaller sorrogat del molt noble governador del present regne de València, vista sua scriptura de demanda de successió ab intestato en la sua Cort posada per lo discret en Francés Joan Cardona, notari, en nom de procurador del Il-lustre don Diego Hurtado de Mendoça, compte de Mélito, tudor e curador de les persones e béns de les Il-lustres dona Mensía de Mendoça, dona Cathalina e dona María de Mendoça, filles del Il-lustre don Rodrigo de Mendoça, quòndam marqués de Atzaneta,

72. Aparecen canceladas en la documentación.

73. Está escrito en el documento original por una mano posterior. 
a huit mes de abril proppassat e la provissió aquella feta, vist los testimonis sobre la dita scriptura e capítols de aquella produhyts y donats e les de posicions de aquelles vist finalment tot ço e quant feya veure e regonéxer per a deguda examinació e liquidació de la present causa, agut acord, consell e liquidació de la present causa, agut acort, consell e deliberació ab lo magnífich micer Ramon del Ort, doctor en cascun dret, regent de assessor hordinari de la sua Cort, nostre Señor Déu Iesuchrist, haver davant los vels de la sua pensa e los Sancts quatre Evangelis de aquell davant si possats e ab molta reverència guardats, per ço que de la sua beneÿta fas lo seu juhí, procedixca dreturer, provehix, desrueix, sentencia i declara en e per la forma segent.

Ihesús.

Attenent e considerant que perdé posicions dels testimonis en la present causa produhyts e donats clarament, consta ya ppar les dites Il-lustres dona Mencía de Mendoça, dona Catherina e dona María de Mendoça ésser filles llegítimes naturals del Il-lustre don Rodrigo de Mendoça, quòndam marqués de Atzenete e de la Il-lustre dona María de Fonsequa, quòndam cònjuges, e de la dita dona Menssía ésser filla major e primo genita del dit Il-lustre marqués don Rodrigo, lo qual consta ésser mort e passat de la present vida en l'altra sens haver fet testament ni altra darrera voluntat sobrevivint aquell les dites dona Mensía, dona Catherina e dona Maria, filles llegítimes e naturals, de aquelles per hon de justícia et àls és dispost e hordenat que totes les terres e stats y béns compressos en lo mayorasgo fet per lo dit Il-lustre marqués don Rodrigo, ab autoritat e confirmació dels Cathòlics Reys, don Fernando e dona Ysabel, reys de Aragó y de la Castella, eterna memòria, pertànyer a la dita Il-lustre dona Mensía de Mendoça, filla mayor e primo genita del dit Il-lustre marqués don Rodrigo e tots los altres béns recahents en la herència de aquella dels quals podrà testar e dispondre, pertànyer e haver pertanygut iure successionis abintestato a les dites Il-lustres dona Mensía, dona Catherina e dona María de Mendoça, filles legítimes e naturals del dit Il-lustre don Rodrigo de Mendoça, quòndam marqués de Atzaneta, per tal et àls pronuncia sentència e ab la present declara lo dit marquesat de Atzeneta, condat del Sit, La Calahorra, Xadraque e sa terra, la vila de Ayora, les baronies de Alberich, Alcocer, e tots los béns, terres y estats compressos en lo dit mayorasgo pertanyent a la dita Il.lustre dona Mensía de Mendoça com a filla mayor e primo genita del dit 
Il-lustre don Rodrigo de Mendoça, quòndam marqués de Atzenete, que tots los altres béns recahents en la herència del Il-lustre marqués don Rodrigo, dels quals que le podia testar e dispondre e pertànyer e haver pertanygut iure successionis abintestato a les dites Il-lustres dona Mencía, dona Catherina e dona María de Mendoça, filles llegítimes e naturals del dit Il-lustre don Rodrigo de Mendoça, quòndam marqués de Atzenete, per quals parts en què aquelles fahedores, fata sentència per lo dit magnífich sorrogat de governador los dia e any dessús dits, senyal del dit magnífich sorrogat de Governador qui la dita sentència dóna e promulga, Hort per assessor.

Presents foren per testimonis a la publicació de la dita sentència e declaració los discrets en Franscesch Fernando e Francesch Casala, habitants de València.

Registrata in XIII manu litigiorum Curie gubernatoris Valencie anni MDXXIII, folio XVI. ${ }^{a}, I^{a}$

E perquè alguts trellat del dels llibres eregís tres de la Cort de la governació de València fehisia donada yo, Joan Llorens Roures, nou enlloc del scrivà de la dita Cort, ací pose mon acostumat signe. L. R.

\section{Bibliografía}

Almenara Sebastià, Miquel y PARdo Molero, Juan Francisco, «Borja-Centelles: una polémica familiar en la Valencia del XVI», en Santiago La Parra y Maria Toldrà (eds.), Francesc de Borja, home del Renaixement, sant del Barroc, València, PUV, 2012: 25-40.

ArCiniegA, Luis, El monasterio de San Miguel de los Reyes, Valencia, Biblioteca Valenciana, 2001.

ARIÈs, Philippe, El hombre ante la muerte, Madrid, Taurus, 1983.

Benito Goerlich, Daniel, El Real Monasterio de la Santísima Trinidad, Valencia, Biblioteca Valenciana, 1998.

CALDERÓN RANGEL, Avelino, Lecciones de derecho hereditario: sucesión ab-intestato, Bucaramanga, Editorial UNAB, 2001.

CARrasco Martínez, Adolfo, «Los Mendoza y lo sagrado. Piedad y símbolo religioso en la cultura nobiliaria», Cuadernos de Historia Moderna, 25 (2000): 233-269. Disponible en: http://revistas.ucm.es/index.php/CHMO/article/ view/CHMO0000220233A 
CATAlina GARCÍA, Juan, «El segundo matrimonio del primer marqués del Cenete», en Juan Valera (ed.), Homenaje a Menéndez Pelayo en el año vigésimo de su profesorado. Madrid, Victoriano Suárez, 1899: 665-681.

DíAz LóPEZ, Julián Pablo, ««Mueran los perros cristianos.» Textos sobre el Marquesado del Cenete en la década de 1520», Revista del CEHGR, 23(2011): 209-227. Disponible en: http://www.cehgr.es/revista/index.php/cehgr/article/ view/11

Domínguez Ortiz, Antonio, Las clases privilegiadas en el Antiguo Régimen, Madrid, Ediciones Istmo, 1973.

Duran, Eulàlia (ed.), Cròniques de les Germanies, València, Tres i Quatre, 1984. Escolano, Gaspar, Segunda parte de la Década primera de la historia de la insigne y coronada ciudad y reyno de Valencia, Valencia, Pedro Patricio Mey (impr.), 1611.

Espinar Moreno, Manuel, Ruiz PÉRez, Ricardo y Ruiz PÉrez, Rafael, Documentos para el Estudio del Marquesado del Cenete (1462-1542), Granada, Grupo de Autores Unidos, 1985.

FAlOMir FAUS, Miguel, «Sobre el marqués del Cenete y la participación valenciana en la castillo de la Calahorra», Archivo Español de Arte, 63/250 (1990): 263-270.

FALOMIR FAUS, Miguel y MARÍAS, Fernando, «El primer viaje a Italia del marqués de Zenete», Anuario del departamento de Historia y Teoría del Arte, 6 (1994): 101-120. Disponible en: https://revistas.uam.es/anuario/article/view/2551

Febrer Romaguera, Manuel Vicente, Ortodoxia y Humanismo: el Estudio General de Valencia durante el rectorado de Joan de Salaya (1525-1558), Valencia, PUV, 2003.

FELIPO ORTS, Amparo, «El proyecto universitario de Mencía de Mendoza», en Vicente S. Olmos (coord.), Doctores y escolares: II Congreso Internacional de Historia de las universidades hispánicas, Valencia, PUV, 1995: 141-154.

FELIPO ORTS, Amparo, Autoritarismo monárquico y reacción municipal: la oligarquía urbana de Valencia desde Fernando el Católico a las Germanías, Valencia, PUV, 2004.

FELIPO ORTS, Amparo, Las arcas de la ciudad: gestión municipal e intervencionismo real en Valencia (1517-1707), Valencia, PUV, 2008.

FELIPO ORTS, Amparo, y PÉREZ APARICIO, Carmen, La nobleza valenciana en la Edad Moderna, Valencia, PUV, 2014. 
Fernández Collado, Ángel, Historia de la Iglesia en España. Edad Moderna, Toledo, Instituto Teológico San Ildefonso, 2007.

FERNÁNDEZ GÓMEZ, Margarita, «El autor del Codex Escurialensis 28-II-12», Academia: Boletín de la Real Academia de Bellas Artes de San Fernando, 74 (1992): 123-162. Disponible en: http://www.cervantesvirtual.com/nd/ ark:/59851/bmchm5n8

FERRER DEL Río, Estefania, «La instrucció ideal del príncep humanista a través d'Erasme, Vives i els tractadistes posteriors», Estudis: Revista d'Història Moderna, 41 (2015), 91-112. Disponible en: http://roderic.uv.es/ handle/10550/55056

FERRER DEL Río, Estefania, «El primer enterramiento del I marqués del Cenete, Rodrigo Díaz de Vivar y Mendoza, en el convento de la Santísima Trinidad de Valencia», Chronica Nova, 32 (2016), 245-258. Disponible en: http://revistaseug.ugr.es/index.php/cnova/article/view/2880

FERRER DEL Río, Estefania, «De la bula de Julio II (1504) a las conclusiones de fray Pedro de Álava (1594): el largo proceso de validación del segundo matrimonio de Rodrigo de Mendoza, primer marqués del Cenete», Manuscrits: Revista d'història moderna, 34 (2016), 13-34. Disponible en: http://revistes. uab.cat/manuscrits/article/view/v34-ferrer

FERRER VAlLS, Teresa, "Corte virreinal, humanismo y cultura nobiliaria en la Valencia del siglo XVII», en Luis Miguel Enciso y José Miguel Sánchez (coords.), Reino y ciudad: Valencia en su historia, Madrid, Caja Madrid Fundación, 2007: 185-200.

Flandrin, Jean-Louise, Orígenes de la familia, Barcelona, Editorial Crítica, 1979. FOUlCHÉ-DelbosC, Raymond, «Testament du Marquis de Santillane», Revue hispanique: recueil consacré à l'étude des langues, des littératures et de l'histoire des pays castillans, catalans et portugais, 67 (1911): 114-133.

FrANCO SilVA, Alfonso, «La herencia patrimonial del gran Cardenal de España D.

Pedro González de Mendoza», Historia. Instituciones. Documentos, 9 (1982):

453-491. Disponible en: https://idus.us.es/xmlui/handle/11441/22173

Franco Silva, Alfonso, «Las baronías del Gran Cardenal de España Don Pedro González de Mendoza», en Lluís de Santàngel i el seu temps, València, Ajuntament de València, 1992: 217-227.

GARCÍA CÁRCEL, Ricardo, «Germana de Foix i les Germanies», en Rosa E. Ríos Lloret y Susana Vilaplana Sanchis (dirs.), Germana de Foix i la societat cortesana del seu temps, València, Generalitat Valenciana, 2006: 35-49. 
García Fernández, Máximo, Los castellanos y la muerte. Religiosidad y comportamientos colectivos en el Antiguo Régimen, Valladolid, Junta de Castilla y León, 1996.

GARCíA PÉREZ, Noelia, «Modelos de enterramiento, modelos de patronazgo: la Capilla de los Tres Reyes del Convento de Santo Domingo de Valencia y los Marqueses del Cenete», IMAFRONTE, 19-20 (2007-2008): 63-74. Disponible en: http://revistas.um.es/imafronte/article/view/138171

Gómez Lorente, Manuel, El marquesado del Cenete (1490-1523), Granada, Universidad de Granada, 1990.

GÓMEZ-FERRER, Mercedes, «El marqués del Zenete y sus posesiones valencianas. Mentalidad arquitectónica y artística de un noble del Renacimiento», Anuario del Departamento de Historia y Teoría del Arte, 22 (2010): 27-46. Disponible en: https://revistas.uam.es/anuario/article/view/2323

GÓMEZ-FERRER, Mercedes, «Las almonedas de los libros del marqués de Zenete en 1529 y 1535 en Valencia», Lemir: Revista de Literatura Española y del Renacimiento, 14 (2010): 231-246. Disponible en: http://parnaseo.uv.es/ Lemir/Revista/Revista14/13_Gomez_Mercedes.pdf

LARA RóDENAS, Manuel José de, «Ilegitimidad y familia durante el Antiguo Régimen: actitudes sociales y domésticas», en Ángel Rodríguez Sánchez y Antonio Peñafiel Ramón, Familia y mentalidades, Murcia, Universidad de Murcia, 1997: 113-129.

LORENZO PINAR, Francisco Javier, Actitudes religiosas ante la muerte en Zamora en el siglo XVI: un estudio de mentalidades, Zamora, Instituto de Estudios Zamoranos «Florián de Ocampo» (CSIC) Diputación de Zamora, 1989.

MArCH, José María, Niñez y juventud de Felipe II: documentos inéditos sobre su educación civil, literaria y religiosa y su iniciación al gobierno (1527-1547), Madrid, Ministerio de Asuntos Exteriores, 1942.

MARCH, José María, «El primer marqués del Cenete. Su vida suntuosa». AEA, 24/93 (1951): 47-66.

MARÍAS, Fernando, «Sobre el Castillo de la Calahorra y el Codex Escurialensis», Anuario del Departamento de Historia y Teoría del Arte, 2 (1990): 117-130. Disponible en: https://revistas.uam.es/anuario/article/viewFile/2625/2794 MARÍAS, Fernando, «El 'Codex Escurialensis' problemas e incertidumbres de un libro de dibujos de antigüedades del último Quattrocento», Reales Sitios: Revista del Patrimonio Nacional, 163 (2005): 14-35. 
MARTín Civantos, José María, «El marquesado del Zenete, un modelo de implantación castellana en el Reino de Granada», Chronica Nova, 30 (2003-2004): 371-400. Disponible en: http://revistaseug.ugr.es/index.php/cnova/article/ view/1897

PEREA RodríGUEZ, Óscar, Estudio biográfico sobre los poetas del Cancionero General, Madrid, CSIC, 2007.

Pérez Boyero, Moriscos y cristianos en los señoríos de Granada (1490-1568), Granada, Universidad de Granada, 1997.

PONS FUSTER, Francisco, «La germanía del notario Joan Sobrevero y los mercaderes», Estudis: Revista de Historia Moderna, 33 (2007): 117-148. Disponible en: http://roderic.uv.es/handle/10550/34427

QUAS, Luis de, La Germanía de Valencia, Valencia, Maxtor, 2006.

Ruiz García, Elisa y CARCEller Cerviño, María del Pilar, «La biblioteca del II duque de Alburquerque (1467-1526)», Anuario de Estudios Medievales, 32/1 (2002): 361-400. http://dx.doi.org/10.3989/aem.2002.v32.i1.238

RUIZ PÉREZ, Ricardo, «El magrán, impuesto decisivo en la progresiva señorialización del marquesado del Cenete durante la época morisca», Chronica Nova, 14 (1984-1985): 293-328. Disponible en: http://hdl.handle.net/10481/26035

Ruiz PÉREZ, Ricardo, «La construcción del castillo-palacio de La Calahorra (Granada). Fuentes, causas y nuevas aportaciones a propósito del V Centenario», Revista del Centro de Estudios Históricos de Granada y su Reino, 26 (2014): 167-200. Disponible en: http://www.cehgr.es/revista/index.php/ cehgr/article/view/80

SÁNCHEZ CANTÓn, Francisco Javier, La biblioteca del marqués del Cenete iniciada por el Cardenal Mendoza (1470-1523), Madrid, CSIC, 1942.

SCAGLIA, Gustina, «El Codex Escurialensis llevado por el artista a La Calahorra en el otoño de 1509», Archivo Español de Arte, 77/308 (2004): 375-383. http:// dx.doi.org/10.3989/aearte.2004.v77.i308.219

SCHIFF, Mario, La bibliothèque du Marquis de Santillane, París, E. Buillon, 1906. SOLERVICENS BO, Josep Vicent, «La literatura humanística a la selecta biblioteca de Mencía de Mendoza, Marquesa del Cenete, Duquessa de Calàbria i deixebla de Joan Lluís Vives», en Jordi Pérez Durà y Ferran Grau Codina (eds.), La Universitat de València i l'Humanisme: Studia Humanitatis i renovació cultural a Europa i al Nou Món, València, PUV, 1906: 313-324.

SORIA MESA, Enrique, Señores y oligarcas: los señoríos del Reino de Granada en la Edad Moderna, Granada, Universidad de Granada, 1997. 
VAlOR MONCHO, Pilar, «El Consell General y la lucha por el poder municipal: origen y desarrollo de las Germanías de Valencia», Estudis: Revista de Historia Moderna, 26 (2000): 227-242. Disponible en: http://www.uv.es/dep235/ PUBLICACIONS_III/PDF112.pdf

VAlOR MONCHO, Pilar, «Los miembros del Consell General de Valencia», Revista de Historia Moderna. Anales de la Universidad de Alicante, 19 (2001): 11-38. http://dx.doi.org/10.14198/RHM2001.19.01

VARELA, Julia, Modos de educación en la España de la Contrarreforma, Madrid, De la Piqueta, 1983. 